\title{
RELAÇÕES ENTRE FAMÍLIA E ESCOLA E SUAS IMPLICAÇÕES DE GÊNERO
}

\author{
MARIA EULINA PESSOA DE CARVALHO \\ Centro de Educação - UFPB
}

\begin{abstract}
RESUMO
A política educacional recente, de caráter neoliberal, está cobrando a participação dos pais na gestão da escola pública e no dever de casa, tanto nos Estados Unidos quanto no Brasil. Tal política tem implicaçôes de classe e gênero: quando a escola conta com a família, pressupóe um modelo de familia com capital econômico e simbólico e com uma mãe disponível e prioritariamente dedicada à educação dos filhos. Os formuladores dessas políticas não consideram a relação entre modelos de organização curricular e instrucional e organização familiar, nem a assimetria de gênero que faz recair a responsabilidade pela educação infantil sobre as mulheres, tampouco as mudanças e variaçôes na organização familiar. Ao desviar o foco da melhoria educacional da escola e da sala de aula para a familia e o lar, este tipo de politica pode produzir dois efeitos perversos: penalizar as familias (sobretudo as mães) e converter diferenças de capital econômico, cultural e social em resultados educacionais desiguais.

POLIITICASEDUCACIONAIS-GESTÃO-ESCOLASPÚBLICAS-FAMÍLIAS
\end{abstract}

\section{ABSTRACT}

THERELATIONSHIPBETWEEN THEFAMILYAND THESCHOOL ANDITS GENDERIMPLICATIONS. Recent neo-liberal educational policy, both in the United States and in Brazil, is calling for parental involvement in school decision-making and homework. Such a policy carries class and gender implications: schools that count on families assume a single family model, with economic and symbolic capital, and an available mother committed to her children's education. Policymakers have neither considered the relationship between models of curricular and instructional organization and family organization, nor the gender asymmetry that places responsibility for children's education mostly on females, nor change and variation in family arrangements. By shifting the focus of educational improvement from the school and classroom to the home and family, this policy is likely to produce two undesirable effects: to penalize families (especially mothers), and convert economic, cultural and social capital differences into different educational outcomes. 


\section{CONTRIBUIÇÃO DA FAMÍLIA À APRENDIZAGEM E SUCESSO ESCOLAR}

Tradicionalmente a família tem estado por trás do sucesso escolar e tem sido culpada pelo fracasso escolar. Quem não conhece o caso, comum no âmbito das famílias de classe média e das escolas particulares, da mãe que acompanha assiduamente o aprendizado e o rendimento escolar do filho, filha ou filhos, que organiza seus horários de estudo, verifica o dever de casa diariamente, conhece a professora e freqüenta as reuniões escolares? E quem não conhece o discurso, freqüente no âmbito da escola pública que atende às famílias de baixa renda, da professora frustrada com as dificuldades de aprendizagem de seus alunos e que reclama da falta de cooperação dos pais?

Com efeito, o sucesso escolar tem dependido, em grande parte, do apoio direto e sistemático da família que investe nos filhos, compensando tanto dificuldades individuais quanto deficiências escolares. Trata-se, em geral, de família dotada de recursos econômicos e culturais, dentre os quais destacam-se o tempo livre e o nível de escolarização da mãe, expressos no conceito de capital cultural de Bourdieu (1987). A família que está por trás do sucesso escolar, salvo exceções, ou conta com uma mãe em tempo integral - ou uma supermãe, no caso daquelas que trabalham muitas horas - exercendo o papel de professora dos filhos em casa, ou contratando professoras particulares para as chamadas aulas de reforço escolar e até mesmo psicólogas e psicopedagogas, nos casos mais difíceis.

As escolas têm contado com a contribuição acadêmica da família de duas maneiras: (a) construindo o currículo (e o sucesso escolar) implicitamente com base no capital cultural similar herdado pelos alunos, isto é, com base no habitus ou sistema de disposições cognitivas adquiridas na socialização primária ou educação doméstica, o que supõe afinidade cultural entre escola e família (Bourdieu, 1977; Bourdieu, Passeron, 1977); e (b) enviando o dever de casa de modo a capitalizar explicitamente o investimento dos pais, o que requer certas condições materiais e simbólicas, isto é, tempo livre, recursos econômicos (para equipar o lar com livros, computadores, contratar professores particulares) e adesão ao papel parental de professor-coadjuvante, tradicionalmente assumido pela mãe (Carvalho, 1997).

Entretanto, por ser considerado natural, expressão do amor e do dever dos pais, o apoio da família ao sucesso escolar ainda permanece mais implícito do que explícito na pesquisa e política educacional, bem como na prática escolar. Igualmente implícitas permanecem as relações de classe e, sobretudo, de gênero, que compõem os modelos de família que conduzem ao sucesso ou ao fracasso escolar.

\section{ENFOQUE DA PESQUISA E POLÍTICA EDUCACIONAIS}

A pesquisa educacional americana, por exemplo, vem focalizando o envolvimento dos pais na educação como um recurso para o sucesso escolar desde a década de 60 
(Henderson, Berla, 1994), quando o famoso Relatório Coleman (Coleman et. al., 1966) apontou a importância das características familiares (em detrimento dos recursos físicos e financeiros escolares) na explicação do aproveitamento escolar inferior das minorias étnicas. A teoria do déficit cultural influenciou tanto a pesquisa subseqüente sobre os processos familiares de socialização infantil, que precedem e supostamente causam o aproveitamento escolar, quanto as intervenções no âmbito da família, visando prevenir o fracasso escolar dos estudantes em situação de desvantagem social por meio de programas de educação compensatória que envolviam a formação parental (parent education), mais especificamente, o treinamento das mães (Scott-Jones, 1993). Nesse sentido, desde 1982, a Associação Americana de Pesquisa Educacional - Aera - tem um grupo denominado Famílias como Educadoras, com o objetivo de estudar os processos sociais na família e as relações casaescola que apóiam a educação e o desenvolvimento infantis (Families as Educators, 1996). De fato, a produção científica sobre o tema tem crescido significativamente (Henderson, Berla, 1994).

Fomentadora da pesquisa e por ela legitimada, a política educacional americana passou a incentivar explicitamente a responsabilidade da família pelo sucesso escolar desde a década de 80 (Department of Education, 1987; Chavkin, 1993; Henderson, Berla, 1994; Cibulka, Kritek, 1996), no contexto de restrições orçamentárias impostas ao sistema escolar (Michigan State Board of Education, 1982), das pressões do setor produtivo por uma nova qualidade educacional (National Commission on Excellence in Education, 1983; Barton, Coley, 1992) e da onda conservadora em prol dos valores familiares e trabalho duro. Concebida como um papel cultural (Hoover-Dempsey, Sandler, 1997), necessário e benéfico, e legitimada pela pesquisa em sua importância e eficácia (Henderson, Berla, 1994), a participação dos pais na educação escolar tem sido retoricamente construída tanto como problema quanto como solução para elevar a produtividade escolar e, em especial, o aproveitamento acadêmico dos grupos em desvantagem social em prol do sucesso tanto do indivíduo quanto da nação (Swap, 1993). De acordo com o discurso oficial, essa política é corroborada por um conjunto de pesquisas que sugerem que o maior envolvimento dos pais está associado a melhores notas em matemática e linguagem, menor probabilidade de suspensão, expulsão ou evasão escolar, e maior participação do estudante em atividades extra-curriculares (National Education Goals Panel, 1995, p.3; United States, 1987). Todavia, na medida em que o envolvimento dos pais não pode ser facilmente isolado e medido como uma variável (Lazar, Darlington, 1978) ou conclusivamente apontado como benéfico para o aproveitamento escolar (White, Taylor, Moss, 1992), o argumento (pretensamente científico) a seu favor afigura-se claramente ideológico.

De fato, o valor do envolvimento dos pais na educação tornou-se um truísmo aceito unanimemente dentro de um amplo espectro de posições políticas nos Estados Unidos: conservadores e liberais, religiosos fundamentalistas e humanistas seculares, to- 
dos endossam-no como um componente fundamental da escolarização bem-sucedida (Casanova, 1996). Ademais, enquanto o enfoque anterior sobre a família como educadora restringia-se à pré-escola e às primeiras séries, o enfoque atual inclui o envolvimento dos pais também na educação de adolescentes (Jackson, 1989) como estratégia de prevenção da indisciplina escolar e da delinqüência juvenil. Por outro lado, a ênfase na diversidade cultural também tem sido incorporada a programas de educação familiar dirigidos aos imigrantes que combinam educação infantil e de adultos (Scott-Jones, 1993; Programs for Educational Opportunity, 1995; Valdes, 1996). Os educadores progressistas, por sua vez, vêem o "fortalecimento" ' dos pais como estratégia para estimular a participação no âmbito da escola pública, tanto na gestão escolar quanto nas decisões curriculares (Fine, 1993; Henderson, Berla, 1994). Enfim, a promessa de uma relação produtiva entre a escola e a família inclui ganhos para a família (coesão, "empoderamento"), para a escola (eficácia), para os estudantes (o sucesso de todos) e para a sociedade (a construção democrática a partir da base e do cotidiano).

Em 1994, sob o Governo Clinton, o envolvimento dos pais na educação escolar tornou-se meta da educação nacional americana, expressa como uma desejável parceria entre família e escola, em que cabe aos pais um papel específico no desenvolvimento acadêmico (além do desenvolvimento social e emocional) de seus filhos no lar (National Education Goals Panel, 1995). A parceria família-escola é, então, oficialmente apresentada como solução para várias necessidades aparentemente compatíveis: dos pais e do lar, sobretudo nos casos de crianças em desvantagem social, portadoras de características especiais e/ou bilíngües (imigrantes); de reforço acadêmico no lar, por meio de políticas explícitas de dever de casa; de participação dos pais na tomada de decisões educacionais na escola; de financiamento adequado das escolas; e, de padrões elevados de desempenho escolar e docente (National Education Goals Panel, 1995, p. 13). É na implementação de programas de parceria família-escola que a pesquisa educacional é agora chamada a concentrar-se (Epstein, 1996).

Objeto de políticas escolares específicas desde a década de 80 (antes, portanto, da formalização do envolvimento dos pais em nível nacional), o dever de casa já vinha há muito penetrando silenciosamente os lares americanos (Roderique et al., 1994). Com efeito, as políticas de dever de casa vêm redefinindo o lar como uma extensão da sala de aula e o dever de casa como uma tarefa a ser realizada fora do horário escolar, de prefe-

I. Em inglês, empowermenté um processo eminentemente educativo de desenvolvimento da auto-suficiência e exercício da força coletiva: aquisição de controle sobre a própria vida, desenvolvimento de habilidades de definir e implementar as próprias agendas de mudança social, organizar-se coletivamente e colocar demandas ao Estado (León, 1997; Medel-Añonuevo, 1997; Young, 1997). Segundo Srilatha Batliwala (apud Medel-Añonuevo, 1997, p. 83, tradução minha), "o empoderamento é o processo - e o resultado do processo - mediante o qual os membros sem poder ou menos poderosos de uma sociedade ganham maior acesso e controle sobre os recursos materiais e o conhecimento, desafiam as ideologias da discriminação e subordinação, e transformam as instituições e estruturas através das quais o acesso e controle desiguais sobre os recursos são sustentados e perpetuados." 
rência, em casa. Uma das funções declaradas do dever de casa é manter os pais informados e envolvidos no aprendizado de seu filho/a, mas sua não-realização acarreta conseqüências, entre as quais a detenção do estudante após o horário da escola (Conover, 1990; East Lansing Educational Foundation, 1996; Murphy, 1996). Por outro lado, o dever de casa tornou-se parte integral da avaliação da aprendizagem, correspondendo de $40 \%$ a $60 \%$ da nota (especialmente a partir da sexta série), mesmo quando é pontuado apenas pela realização completa e pontualidade na entrega. Exemplo da perspectiva segundo a qual o dever de casa deve ser incorporado ao cotidiano familiar é a modalidade interativa do dever de casa, com seções para os pais desenvolverem juntamente com os filhos (por exemplo, na cozinha, aplicando Matemática e Ciências na preparação do jantar), comentarem e assinarem (Epstein, 1994; Gallagher, 1994; Olympia et al., 1994; Mafnas et al., 1993; Orman, 1993; Wisdom, 1993), exemplificando a perspectiva da escola, segundo a qual o dever de casa deve ser incorporado ao cotidiano familiar.

No Brasil a relação família-escola tem sido pouco estudada, embora o dever de casa também faça parte de nossa tradição educacional. No caso da escola privada de classe média supõe-se que a sua aceitação (principalmente pelos pais) como uma prática rotineira esteja associada ao fato de a jornada letiva diária e a anual serem percebidas como curtas e insuficientes para o progresso escolar. No caso da escola pública, reconhece-se que os baixos níveis de escolaridade e renda de sua clientela desestimulam tanto a participação dos pais nas reuniões escolares quanto a adoção de deveres de casa. Agora, porém, o modelo de envolvimento dos pais na escola está sendo assimilado no contexto da atual tendência à descentralização da gestão educacional e melhoria da produtividade e qualidade escolar no sistema de ensino público.

Com efeito, a retórica liberal do Banco Mundial está vendendo aqui a idéia da necessidade do apoio dos pais e da comunidade, bem como da maior freqüência dos deveres de casa, como "fatores determinantes da eficácia escolar" (Heneveld, 1994, p. 6). Assim, o Projeto Nordeste (Projeto de Educação Básica para o Nordeste), patrocinado pelo Ministério da Educação e do Desporto - MEC - e pelo Banco Interamericano de Desenvolvimento - Bird -, pretende melhorar a qualidade da educação fundamental na região prescrevendo a contribuiçã̃o dos pais e da comunidade. De acordo com o projeto, os pais e a comunidade dão apoio eficaz quando:

\footnotetext{
I. O aluno freqüenta a escola com saúde e aptidão para aprender.

2. Os pais e a comunidade dão apoio financeiro e/ou material para a operação da escola.

3. Há comunicação freqüente entre o corpo docente e os pais.

4. Os membros da comunidade e os pais auxiliam na instrução.

5. A comunidade desempenha um papel com significativa autoridade na escola.

(Heneveld, 1994, p. 35)
} 
Nessa região, caracterizada pela pobreza, altos níveis de analfabetismo, distância entre a cultura escolar e a cultura popular, e um sistema escolar público que tradicionalmente nunca adotou a prática do dever de casa $^{2}$, os pais representam insumos para a melhoria da eficácia escolar a serem aferidos por meio de certos indicadores. Assim, a aptidão para aprender é medida pela evidência de que leituras, conversações e brincadeiras dirigidas ocorrem no lar, pressupondo a conexão entre atividades domésticas e currículo escolar. Ajudar com a instrução (além de apoiar financeira e materialmente a escola) é traduzido como apoiar e monitorar os deveres de casa, servir como tutor, fonte de informações e audiência em relação ao trabalho escolar dos estudantes (Heneveld, 1994). Deveres de casa freqüentes, isto é, mais de uma vez por semana, são prescritos a partir da quarta série, com conteúdo adequado à idade dos alunos e ao ambiente familiar (Heneveld, 1994).

Pesquisadores brasileiros (atrelados à formulação de políticas financiadas pelo Banco Mundial) também estão reproduzindo a lógica das pesquisas e políticas americanas citadas. Portela, Bastos, Vieira, Holanda e Matos (Banco Mundial, 1997), estudando a avaliação da escola pelos usuários e constatando limites ao envolvimento das famílias na vida escolar, recomendam a valorização da participação dos pais. Castro, Pestana, Fini, Vema e Waiselfisz (Banco Mundial, 1997), analisando os resultados do Saeb/95, recomendam maior comunicação da escola com os pais e extensão do período de estudo via lição de casa. Mendonça e Barros (Banco Mundial, 1997), considerando a associação entre meIhores resultados escolares das crianças e maior nível de escolaridade dos adultos e com base na hipótese de que pais mais exigentes influenciam o desempenho das escolas, também recomendam "a participação dos pais no processo educacional, uma vez que os fatores familiares geram impacto sobre os resultados educacionais" (p. 83). Outras pesquisas, ademais, têm ressaltado o nível de escolaridade da mãe como determinante do desempenho escolar do aluno (Banco Mundial, 1997).

Assim, tanto nos Estados Unidos como no Brasil, a fórmula da relação famíliaescola seria a seguinte: mais envolvimento dos pais em casa equivale a maior aproveitamento e permanência na escola por parte dos alunos; mais participação dos pais na escola resulta em melhores escolas. Embora alguns (poucos) estudos americanos tenham enfocado conflitos de classe e cultura nas interações família-escola (Lareau, 1993; Wong Fillmore, 1990), tanto lá como cá predomina o silêncio sobre a problemática de gênero subjacente.

2. Não tenho dados empíricos para comprovar tal afirmação, até porque a pesquisa não tem enfocado o dever de casa como tema. No âmbito da minha experiência, com incursões informais em escolas urbanas e rurais da Paraíba, o dever de casa não era ou é prática costumeira. Acredito que quando adotado no sistema público trata-se mais de iniciativa de professoras que seguem o modelo da escola particular (ou tentam segui-lo, freqüentemente sem sucesso) do que de uma orientação oficial, ao menos por enquanto. 


\section{EFEITOS PERVERSOS DO MODELO DE PARCERIA FAMÍLIA-ESCOLA}

Ao acentuar significativamente a responsabilidade dos pais pelo aproveitamento e sucesso escolar do aluno e pela eficiência e eficácia da escola, a política de articulação família-escola esboçada no modelo descrito acima traz uma série de implicações e flexibilidades ainda não examinadas pela pesquisa.

Do ponto de vista histórico, essa política aparentemente tenta reverter o projeto da educação pública moderna que, precisamente, se sobrepôs à educação da família e da comunidade. Assim, o papel acadêmico atribuído à família nega a especificidade da educação escolar e afeta o papel profissional docente, contra toda uma história de diferenciação institucional, especialização funcional (Bidwell, 1991; Tyack, 1976) e profissionalização do magistério. Além disso, apaga a distinção entre educação formal e informal, reduz a educação à escolarização e confunde o papel paterno/materno com o papel docente. E, contraditoriamente, desconhece as mudanças nas formas de organização familiar que vêm distanciando um grande número de famílias do modelo de família patriarcal em que a mãe se dedica integralmente aos filhos e à vida familiar, omitindo, portanto, as razões pelas quais a maioria dos pais/mães não colabora da maneira que as escolas e as professoras esperam.

Para a escola e para o professor essa política também traz contradições. Por um lado, amplia o escopo de atuação da escola ao pressupor a reeducação dos pais/mães (para a participação na escola controlando o currículo, o orçamento escolar e o desempenho docente, e para a participação no lar monitorando o dever de casa) como precondição para a educação das crianças. Por outro lado, ao sugerir que os pais atuem como professores em casa, diminui o status profissional, o saber e a formação especializada da professora e do professor. Finalmente, ao assinalar aos pais o papel de inspetores das escolas e dos professores, pode contribuir para minar a confiança e acentuar a animosidade entre professores/as, diretores/as e pais/mães.

Para os pais (sobretudo para as mães) e para a vida familiar, essa política impõe tensões. Em primeiro lugar, ela adota um modelo único de família: afluente, com uma esposa e mãe em tempo integral (Thorne, Yalom, 1992), do qual se distancia um grande número de famílias nestes tempos de crescentes índices de pobreza econômica, emprego materno, estresse familiar, divórcio e mulheres chefes de família. Ao impor aos pais a concepção de que o lar deve ser um local para o desenvolvimento explícito e intencional do currículo escolar, obriga-os a converterem as atividades familiares em extensões das atividades de sala de aula, em detrimento de suas próprias opções educacionais e de suas necessidades de lazer e de descanso. E, ao sugerir aos pais que participem da gestão escolar, demanda não apenas tempo e conhecimento individuais, mas a difícil tarefa de organização coletiva.

As conseqüências antidemocráticas dessa política são previsíveis. Ao atribuir à família a obrigação de propiciar o desenvolvimento acadêmico das crianças, criando um am- 
biente educativo doméstico alinhado ao currículo escolar, omitindo as diferenças de capital econômico, social e cultural (Bourdieu, 1987) entre os diversos grupos sociais que se traduzem em vantagem ou desvantagem escolar, tal política poderá acentuar as desigualdades de aprendizagem e resultados escolares, culpando perversamente os pais e mães pelo fracasso escolar. Ao mesmo tempo, ao sobrepor o currículo escolar às práticas educativas domésticas e ao privilegiar um estilo particular de exercício da paternidade/maternidade, poderá enfraquecer a autonomia da família e a liberdade dos pais e mães. Poderá, ainda, ameaçar a pluralidade cultural ao impor a uniformidade cultural para além dos muros da escola pública, penetrando no reduto da vida privada.

Atribuir à família a responsabilidade pela qualidade da escola pública (através da participação nos Conselhos Escolares, por exemplo) também pode acarretar complicações: omitem-se possíveis conflitos tanto entre educadores profissionais e pais (Waller, 1965; Bliken, 1995) que não têm igual poder de decisão sobre a educação escolar, quanto entre educadores e grupos de pais de poder diferenciado, que podem divergir sobre conteúdos e valores no currículo, por exemplo, e entrar em competição a fim de influenciarem as políticas e práticas escolares, com conseqüências igualmente antidemocráticas (Casanova, 1996; Henry, 1996; Smrekar, 1996).

Da perspectiva das relações de gênero a política pode ter como efeito indesejável o reforço da divisão sexual do trabalho de cuidado e educação infantil que, tradicionalmente, tem relegado essa responsabilidade exclusivamente às mulheres, ampliando nesse caso os deveres domésticos das mães de modo a incluir a instrução acadêmica. Outro efeito possível é o reforço da discriminação de classe, raça e gênero, pela criação de estruturas hierarquizadas e diferenciadas de participação escolar, com pais pobres pintando o prédio da escola, mães de baixa renda ajudando a servir a merenda escolar, por exemplo, enquanto mães e pais de classe média atuam como membros dos Conselhos Escolares (Carvalho, 1997).

\section{O DEVER DE CASA, A PRÁTICA ESCOLAR E AS MÃES}

Derivada do modelo de escolarização bem-sucedido das classes médias, baseado em aspirações familiares de ascensão escolar e social, na continuidade cultural entre o lar e a escola, na forma patriarcal de organização familiar e numa pedagogia escolar que requer a contribuição da família pelo dever de casa, a atual política de participação dos pais no processo educacional articula a escola e a família como espaços educativos de forma explícita e totalitária.

Com efeito, é importante diferenciar o envolvimento dos pais na educação dos filhos como atitude individual informal, no contexto de uma cultura de classe e de sua estratégia de ascensão social, da política formal que visa promover a contribuição acadêmica dos pais para a eficácia escolar mediante incentivos positivos e negativos. Assim, essa 
política é totalitária em seus efeitos sobre a família de dois modos: ao penetrar espaços e tempos extra-escolares pela imposição do currículo escolar (a cultura dita científica, a visão de mundo dominante, determinadas ideologias) sobre as culturas familiar e popular no cotidiano doméstico e comunitário; ao tratar a família como objeto de política educacional visando elevar indiretamente a produtividade escolar mediante a utilização do ambiente e tempo familiares, tornando-os mais educacionalmente produtivos de acordo com a perspectiva da escola.

Não se está aqui idealizando positivamente as culturas familiar e popular ou negativamente o currículo escolar, mas defendendo o pluralismo cultural e a liberdade da família para escolher seu "currículo" informal, sem que seus filhos sejam prejudicados no contexto competitivo da avaliação escolar. Uma implicação perversa do dever de casa é que a avaliação do aluno corresponde à avaliação do desempenho dos pais, já que a escola requer o seu apoio. Ora, a missão da escola democrática é precisamente compensar o peso desigual das condições familiares, impedindo que estas repercutam sobre as condições de aprendizagem e, principalmente, sobre a avaliação dos alunos. Portanto, na medida em que afeta direta ou indiretamente a aprendizagem e a avaliação do aluno, a política do dever de casa consagra a iniqüidade educacional.

Ademais, ao repassar parte do trabalho acadêmico para a família, tal política explicitamente desvia o foco de melhoria educacional da sala de aula para o lar. Ao mesmo tempo, as implicações do dever de casa para o trabalho da sala de aula permanecem veladas. De fato, o dever de casa integra uma concepção particular de instrução, de organização da aprendizagem, de trabalho escolar e de papel docente (Carvalho, 1997). Faz diferença planejar e desenvolver o currículo e as atividades escolares, bem como o tempo e a dinâmica da sala de aula, com ou sem o dever de casa. Quem não conhece o tipo de aula que revisa e corrige o dever de casa de ontem e passa e explica o dever de casa de amanhã? Assim, o tempo e as atividades de classe podem continuaro dever de casa, requisitando trabalho extra-classe, ou podem se definir autonomamente, indicando o aumento da produtividade de classe.

Outra implicação totalitária e perversa do dever de casa é que ele impõe não apenas um modelo particular de relação família-escola, mas de família e de papel parental, reforçando a tradicional divisão sexual de trabalho na família. Ora, o modelo típico de ambiente familiar associado ao sucesso escolar baseia-se numa divisão de trabalho em que a responsabilidade pelos filhos ainda recai mais sobre as mães do que sobre os pais. Ademais, ao ser requerida de todos os pais (diferentemente da participação na gestão escolar), a participação acadêmica em casa, ainda que seja inviável para muitos, torna-se praticamente compulsória, devido às sanções negativas óbvias acarretadas pela omissão do dever de casa.

Como já foi dito, o modelo de parceria família-escola pressupõe a típica família de classe média cuja mãe se dedica exclusivamente aos filhos e ao lar. Além de consumir 
tempo significativo das mães, o dever de casa também afeta - e não necessariamente de modo positivo - a organização da vida doméstica (por exemplo, introduzindo sessões de dever de casa após o jantar) e a relação mãe-filho/a, freqüentemente criando pressões e conflitos adicionais. $\bigcirc$ fato mais grave, porém, é que este modelo de família já não é mais predominante. Não é por acaso que vem crescendo a oferta de reforço escolarpor professoras particulares, que atendem os estudantes da vizinhança no seu próprio domicílio ou no domicílio do estudante.

Assim, é importante chamar a atenção para o alcance da política escolar sobre a família e especialmente sobre as mães, explicitando de que forma ela articula implicitamente escola e família como instâncias educativas. Como observa David (1980, 1989), a organização do trabalho (destinada aos homens) e a da escola (destinada às crianças) são incompatíveis tanto em termos da jornada diária (8 horas de trabalho e 4 horas de escola) como da anual ( I I meses de trabalho e 9 meses de escola) porque pressupõem uma mãe disponível diariamente e durante todo o ano. Nesse contexto, a implicação de gênero do dever de casa é um ponto cego da atual política de participação democrática dos pais no processo educacional.

\section{REFERÊNCIAS BIBLIOGRÁFICAS}

AMERICAN EDUCATIONAL RESEARCH ASSOCIATION. Families as educators. Families as Educators Special Interest Group, 1996.

BANCO MUNDIAL, UNICEF. Chamada à ação: combatendo o fracasso escolar no Nordeste. 2.ed. Brasília, 1997. (Programa de Pesquisa e Operacionalização de Políticas Educacionais)

BARTON, P. E., COLEY, R. J. America's smallest school: the family. Princeton, New Jersey: Educational Testing Service, 1992. (Policy Information Center)

BIDWELL, C. Families, childrearing, and education. In: PIERRE, B., COLEMAN, J. S. (eds.). Social Theory for a Changing Society. Boulder: Westview Press; New York: Russell Sage Foundation, 1991. p. 189-93.

BLIKEN, S. K. Schoo/work. gender and the cultural construction of teaching. New York: Teachers College Press, 1995.

BOURDIEU, P. Cultural reproduction and social reproduction. In: KARABEL, J., HALSEY, A. H. (eds.). Power and ideology in education. New York: Oxford University Press, 1977. p. 487-5। I.

The Forms of capital. In: RICHARDSON, J. G. (ed.). Handbook of theory and research for the sociology of education. New York: Greenwood Press, 1987. p. 24 I58. 
BOURDIEU, P., PASSERON, J. C. Reproduction in education, society and culture. Beverly Hills, CA: Sage, 1977.

CARVALHO, M. E. P. Family-schoo/relations. how enhanced parental participation in schooling reinforces social inequality and undermines family autonomy. Michigan, 1997. Tese (dout.) Dep. Teacher Education, Michigan State University.

CASANOVA, U. Parent involvement: a call for prudence. Educational Researcher, v. 25, n. 46, p. 30-2, 1996.

CHAVKIN, N. F. (ed.). Families and schools in a pluralistic society. Albany, NY: State University of New York Press, 1993. p. 217-26.

CIBULKA, J. J., KRITEK, W. J. (eds.). Coordination among schools, families, and communities: prospects for educational reform. Albany, NY: State University of New York Press, 1996.

COLEMAN, J. et al. Equality of educational opportunity report. Washington DC: U.S. Government Printing Office, 1966.

CONOVER, P. J. Detention as a deterrent for late assignments. a study. Boston, 1990. (Paper presented at the annual meeting of the American Educational Research Association) (ERIC Document Reproduction Service N: ED3259I0)

DAVID, M. E. Schooling and the family. In: GIROUX, H. A., McLAREN, P. (eds.). Critical pedagogy, the state, and cultural strugg/e. Albany: State University of New York Press, 1989. p. 50-65.

The State, the family, and education. London: Routledge \& Kegan Paul, 1980.

EAST LANSING EDUCATIONAL FOUNDATION. Student agenda, 1996- /997. East Lansing Public Schools, 1996.

EPSTEIN, J. L. Perspectives and previews on research and policy for school, family, and community partnerships. In: BOOTH, A., DUNN, J. F. (eds.). Family-School links. how do they affect educational outcomes? Mahwah, NJ: Lawrence Erlbaum Associates, 1996, p. 209-46.

School-Home connection: make language arts a family affair. Instructor, v. I03, n. 17, p. 22-3, 1994.

FINE, M. [Ap]parent involvement: reflections on parents, power, and urban public schools. Teachers College Record, v. 94, p. 682-710, 1993.

GALLAGHER, R. A Parent's guide to helping with homework. Learning, v. 22, p. 67, 1994.

HENDERSON, A., BERLA, N. (eds.). A New generation of evidence: the family is crucial to student achievement. Washington, DC: National Committee for Citizens in Education, 1994. 
HENEVELD, W. Planejamento e monitoramento da educação primária. Washington, DC: Banco Mundial, 1994.

HENRY, M. E. Parent-school collaboration: feminist organizational structures and school leadership. Albany, NY: State University of New York Press, 1996.

HOOVER-DEMPSEY, K. V., SANDLER, H. M. Why do parents become involved in their children's education? Review of Educational Research, v. 67, p. 3-42, 1997.

JACKSON, A. Turning points. preparing american youth for the 2 I th century. Washington, DC: Carnegie Council on Adolescent Development, 1989.

LAREAU, A. Home advantage. London: The Falmer Press, 1993.

LAZAR, I., DARLINGTON, R. B. Summary, lasting effects after preschool. Cornell University. 1978. (Consortium for Longitudinal Studies)

LEÓN, M. (comp.) Poder y empoderamiento de las mujeres. Bogotá: T.M. Editores; UN: Facultad de Ciencias Humanas, 1997.

MAFNAS, I. et al. A Contract for Science. Science Scope, v. 17, p.45-8, 1993.

MEDEL-AÑONUEVO, C. Learning gender justice: the challenge for adult education in the $21^{\text {st }}$ century. Adult Education and Development, n. 49, 1997.

MICHIGAN STATE BOARD OF EDUCATION. A Position statement and resource guide on involvement of parents and other citizens in education. Michigan, 1982.

MURPHY, B. School district to make detention a family affair. Detroit Free Press. On line: http://www.freep.com/news/education/qparents25.htm, 2/10/1996.

NATIONAL COMMISSION ON EXCELLENCE IN EDUCATION. A Nation at risk: the imperative for educational reform. Washington, DC: Department of Education, 1983.

NATIONAL EDUCATION GOALS PANEL. The National education goals report. building a nation of learners. Washington, DC: U.S. Government Printing Office, 1995.

NATIONAL STANDARDS FOR PARENT. FAMILY INVOLVEMENT PROGRAMS. National PTA. Chicago, IL, 1997.

OLYMPIA, D. E. et al. Homework: a natural means of home-school collaboration. School Psychology Quarterly, v. 9, p. 60-80, 1994.

ORMAN, S. A. Mathematics backpacks: making the home-school connection. Arithmetic Teacher, v. 40, p. 306-8, 1993.

PROGRAMS FOR EDUCATIONAL OPPORTUNITY. Family math, family science, playtime is science. University of Michigan, School of Education, 1995. 
RODERIQUE, T. W. et al. Homework: a survey of policies in the United States. Journal of Learning Disabilities, v. 27, p. 481-7, 1994.

SCOTT-JONES, D. Families as educators in a pluralistic society. In: CHAVKIN, N. F. (ed.), Families and schools in a pluralistic society. Albany, NY: State University of New York Press, 1993. p. 245-54.

SMREKAR, C. The Impact of school choice and community. in the interest of families and schools. Albany, NY: State University of New York Press, 1996.

SWAP, S. Mc. Developing home-school partnerships. from concepts to practice. New York: Teachers College Press, 1993.

THORNE, B., YALOM, M. (eds.) Rethinking the family. some feminist questions. Revised edition. Boston: Northeastern University Press, 1992.

TYACK, D. Ways of seeing: an essay on the history of compulsory schooling. Harvard Educational Review, v. 46, p. 355-89, 1976.

UNITED STATES. Department of Education. America 2000: an educational strategy. Sourcebook. Washington, DC: US Department of Education, 1991.

What works: research about teaching and learning. Washington, DC: U.S. Department of Education, 1987.

VALDES, G. Con respeto: bridiging the distances between culturally diverse families and schools; an ethnographic portrait. New York: Teachers College Press, 1996.

WALLER, W. The Sociology of teaching. New York: Science Editions, 1965.

WHITE, K. R., TAYLOR, M. J., MOSS, V. D. Does research support claims about the benefits of involving parents in early intervention programs? Review of Educational Research, $v$. 62, p. $91-125,1992$.

WISDOM, C. Growing together: sharing through homework journals. Teaching Pre-K-8, v. 24, p. 93-5, 1993.

WONG FILLMORE, L. Now or later? Issues related to the early education of minority-group children. Early childhood and family education: analysis and recommendations of the Council of Chief State School Officers. New York: Harcourt Brace Jovanovich, 1990. p. 122-45.

YOUNG, K. El Potencial transformador en las necesidades prácticas: empoderamiento colectivo y el proceso de planificación. In: LEÓN, M. (comp.). Poder y empoderamiento de las mujeres. Bogotá: TM Editores; U.N.: Facultad de Ciencias Humanas, 1997. 
